\title{
MODO DE PRODUÇÃO E EDUCAÇÃO: NOTAS PRELIMINARES ${ }^{1}$
}

\author{
MODO DE PRODUCCIÓN Y EDUCACIÓN: NOTAS PRELIMINARES
}

\author{
MODE OF PRODUCTION AND EDUCATION: PRELIMINARY NOTES
}

\author{
José Claudinei Lombardi²
}

\begin{abstract}
Resumo: Este texto faz a crítica à pós-modernidade, à apologia das perspectivas microscópicas, fragmentárias, irracionalistas, ao empirismo tosco. Afirma a atualidade da concepção marxiana e engelsiana para a explicação de tudo quanto existe e a centralidade da categoria modo de produção da vida material dos homens para a explicação e o entendimento das condições históricas expressas nas diferentes formações sociais. A exposição está organizada em 04 partes: na primeira, trata-se dos fundamentos das discussões filosóficas e científicas; na segunda dos fundamentos da concepção materialista e dialética da história; na terceira, discute-se o modo de produção como categoria central da concepção marxista; na quarta parte trata-se da educação e modo de produção. Para a educação marxista, tal qual se expressa na elaboração marxiana e engelsiana, é necessário ir para além do capital, organizar e criar as condições para um salto de qualidade na luta revolucionária do proletariado contra o capital, algo que não é para o futuro. Isto, já vem se dando desde o século XVIII quando o proletariado reivindica, em contraposição à educação burguesa, uma educação que articule trabalho manual e trabalho intelectual, que articule uma formação integral, uma educação que ultrapasse os limites e a alienação posta na educação burguesa. O estabelecimento dos sistemas educacionais não mais em uma perspectiva unilateralmente burguesa, mas com a absorção das contraposições e das reivindicações do proletariado.
\end{abstract}

Palavras-chave: Modo de produção; Pós-modernidade; Educação; Trabalho manual e intelectual.

Resumen: Este texto hace crítica a la posmodernidad, a la apología de las perspectivas microscópicas, fragmentarias, irracionalistas, al empirismo vulgar. Afirma la actualidad de la concepción marxiana y engelsiana para la explicación de todo cuanto existe y la centralidad de la categoría modo de producción de la vida material de los hombres para la explicación y entendimiento de las condiciones históricas expresas en las diferentes formaciones sociales. La exposición está organizada en cuatro partes: en la primera, se trata de los fundamentos de las discusiones filosóficas y científicas; en la segunda, de los fundamentos de la concepción materialista y dialéctica de la historia; en la tercera, se discute el modo de producción como categoría central de la concepción marxista; en la cuarta parte se trata de la educación y modo de producción. Para la educación marxista, tal cual se expresa en la elaboración marxiana y engelsiana, es necesario irse además del capital, organizar y crear las condiciones para un salto de calidad en la lucha revolucionaria del proletariado contra el capital, algo que no es para el futuro. Esto, ya viene dándose desde el siglo XVIII, cuando el proletariado reivindica, en contraposición a la educación burguesa, una educación que articule trabajo manual y trabajo intelectual, que articule una formación integral, una educación que ultrapase los límites de la alienación puesta en la educación burguesa. El establecimiento de los sistemas educacionales no más en una perspectiva unilateralmente burguesa, pero con la absorción de las contraposiciones y de las reivindicaciones del proletariado.

Palabras-clave: Modo de producción; Posmodernidad; Educación; Trabajo manual e intelectual.

Abstract: This text criticizes the post-modernity, the apology from the microscopic, scrappy, irrational perspectives
to the crude empiricism. It claims the present of the Marxist and Engelsist conception for the explanation for
everything that exists and the centrality of the category mode of production in the material life of the men for the
explanation and the understanding of the historical conditions expressed in the different social formations. The
exposure is organized in four parts: the first is about the foundations of the philosophical and scientific arguments;
the second is about the foundations of the materialistic and dialectic conception of the history; in the third is talked
about the mode of production as a central category in the Marxist conception; the fourth part deals with the
education and the mode of production. For the Marxist education, as it is expressed in the Marxist and engelsist
elaboration, it is necessary to go beyond the capital, organize and create the conditions for a quality leap on the 
revolutionary struggle of the proletariat against the capital, something that is not for the future. This has been happening since the $18^{\text {th }}$ century when the proletariat claims, in contrast to bourgeois education, an education that combines manual and intellectual work, which combines a whole degree, an education that goes over the limits and the alienation placed in the bourgeois education. The establishment of educational systems, not in a unilaterally bourgeois perspective anymore, but with the absorption of the counterbalances and of the claims of the proletariat.

Key-words: Mode of production; Post-modernity; Education; Manual and intellectual work.

Começo fazendo uma provocação sobre o atual debate que permeia o embate teóricometodológico da pesquisa educacional, particularmente nas Faculdades de Educação país afora: que sentido faz discutirmos a perspectiva marxista, quando nas Faculdades de Educação é praticamente hegemônica a apologia de uma perspectiva microscópica, fragmentária e irracionalista no trato da problemática questão educacional em todas as suas dimensões e perspectivas? Face às perspectivas novidadeiras, que propugnam uma crítica radical à razão moderna, o rompimento com as concepções filosóficas e científicas vinculadas ao iluminismo, enfim a impossibilidade da revolução, que sentido faz assumirmos pressupostos que são, exatamente, opostos a este fazer acadêmico que, mais que moda, expressa aquilo que vem se produzindo no âmbito da pesquisa educacional e que vai na contramão das reflexões que têm a pesquisa radical, profunda e crítica da realidade, entendida em sua materialidade e em sua totalidade contraditória. Dá para conciliar este quadro de discussões?

Apesar do aparente modismo pós-moderno, que tudo transforma em idealismo alucinado, perdendo a perspectiva de toda e qualquer articulação de uma elaboração acadêmica, caindo no pólo oposto, num empirismo rudimentar, num empirismo tosco que pouco se diferencia do senso comum, penso que uma retomada da concepção marxiana e engelsiana é de grande atualidade, pois ainda é a principal contraposição a toda forma de idealismo, a todo empirismo fenomênico e subjetivismo. Em oposição a estas posturas claramente idealistas, céticas e subjetivistas, a perspectiva marxiana articula uma concepção ao mesmo tempo materialista, dialética e objetivista, explicando tudo o que socialmente existe, tomando o próprio homem como criador e gestor de sua história, o homem vivo e real, que para existir, precisa, antes de mais nada, produzir a sua própria existência. Neste sentido, o modo de produção da vida material dos homens, entendido enquanto totalidade das relações dos homens entre si e dos homens com a natureza, se apresenta como uma categoria central para a explicação e o entendimento das condições históricas mais gerais, no sentido de tomar como objeto de discussão as transformações universais que o capitalismo está assumindo, quanto às discussões mais específicas da realização destas nas diferentes formações sociais.

Organizei minha exposição em 04 partes: na primeira, trato dos fundamentos das discussões filosóficas e científicas; na segunda, trato dos fundamentos da concepção materialista e dialética da história; na terceira, discuto o modo de produção como categoria central da concepção marxista; na quarta parte trato da educação e modo de produção.

\section{Fundamento das concepções filosóficas e científicas}


Tenho me dedicado a discutir, particularmente para melhor entender as diferentes posições metodológicas e teóricas do fazer científico na filosofia e história da educação, quais os aspectos que fundamentam as concepções filosóficas e científicas. Penso que as diferentes concepções filosóficas e científicas se diferenciam em decorrência dos pressupostos onto-gnosiológicos que as caracterizam diferentemente e colocam em confronto uma com as outras. Se perguntarmos à história e à filosofia o que explica a existência de profundas diferenças entre abordagens ideológicas, filosóficas e científicas, a resposta (mesmo que não estando pronta e acabada na história da filosofia) vai nos levar a uma retomada das grandes questões filosóficas que nos fazem entender que existem diferentes concepções porque são diferentes as perguntas e respostas que fazemos às grandes questões relativas ao mundo e ao conhecimento acerca do mundo.

Em síntese, as diferentes concepções o são porque articulam diferentes pressupostos explicativos quanto ao mundo, à vida e ao homem; quanto ao conhecimento e as possibilidades de conhecer e quanto ao fazer e agir dos homens. Enfim, as concepções se articulam a partir de diferentes pressupostos ontológicos, gnosiológicos e axiológicos.

No âmbito da história da filosofia, esta diversidade desemboca nas grandes concepções com as quais ainda nos defrontamos na contemporaneidade, e que são as grandes tradições filosóficas, matrizes clássicas que permeiam o fazer filosófico e científico: a metafísica: (re)fortalecida com a "nova onda" mística e religiosa e pela "nova romanização"; a concepção empirio-positivista - com suas tendências cientificistas, neopositivistas e mesmo transpositivistas; a tradição fenomenológico + hermenêutica - sendo suas principais tendências a própria fenomenologia, a hermenêutica, o culturalismo, o existencialismo, o antipositivismo e da arqueogenealogia; as concepções fundadas na dialética e suas três grandes tendências: a dialética idealista (hegeliana), a dialética marxista e a dialética negativa (teoria crítica ou Escola de Frankfurt); e, finalmente, é preciso incluir os vários ecletismos produzidos no âmbito da filosofia e das ciências, com destaque para a pesquisa histórica e educacional (sobre as quais tenho me debruçado).

\section{Fundamentos da concepção materialista, dialética da história}

Sendo toda concepção fundada sobre pressupostos ontológicos, gnosiológicos e axiológicos, o estudo do conjunto da obra de Marx e Engels nos permite entender como estes clássicos produziram os pressupostos de uma nova concepção no processo de produção da obra conjunta, no confronto crítico com as posições vigentes no período e na medida em que se alargavam os estudos sobre a realidade com a qual se defrontavam, estudos necessários para instrumentalizar o movimento proletário com o qual estavam articulados. Nestes estudos, no debate com as concepções vigentes no seu tempo, iam respondendo questões mais gerais de caráter ontológico, gnosiológico e axiológico. Do conjunto desta elaboração, desembocam numa ontologia - como explicitação do mundo existente, do ser de todas as coisas, de suas determinações e características - que se expressa na materialidade do mundo existente, no entendimento do real como uma totalidade em permanente processo de transformação impulsionada pelas contradições que lhe dão forma e conteúdo. Do ponto de vista da gnosiologia - englobando as questões sobre 
o conhecimento, quanto as suas possibilidades e determinações - crescente e gradativamente foram construindo o ponto de vista de que a matéria é anterior à consciência, que o mundo é cognoscível, que é possível um conhecimento objetivo do mundo e, sendo a realidade contraditória, colocaram a dialética como método de apreensão da realidade como totalidade contraditória, articulando a unidade dialética entre teoria e prática e, principalmente, colocando a prática (histórica) como critério de verdade, no âmbito dessa discussão gnosiológica. A adoção de tais pressupostos levaram à construção de uma concepção profundamente diferente das perspectivas de seu tempo e desembocaram em uma intransigente defesa da necessária unicidade do conbecimento, que expressaram em vários momentos em célebre afirmação quanto à ciência da história, ou quanto à única ciência e que expressava a busca não por um entendimento, parcelar, fragmentário, fenomênico das coisas, mas de um conhecimento que expressava, na materialidade de um cérebro pensante, a articulação do real ou a apreensão da totalidade enquanto totalidade de pensamento. Nunca é demais repetir a conhecida nota de rodapé [cortada no manuscrito, supondo-se que era isso o que pensavam, mas que não deveria ser publicado]:

\footnotetext{
Apenas conhecemos uma ciência, a da história. Esta pode ser examinada sob dois aspectos; podemos dividi-la em historia da natureza e historia dos homens. Porém, estes dois aspectos não são separáveis; enquanto existirem homens, a sua historia e a da natureza, aquilo que se designa por ciência da natureza, não nos interessa aqui; pelo contrário, é-nos necessário analisar em pormenor a história dos homens, pois, com efeito, quase toda a ideologia se reduz a uma falsa concepção dessa história ou ao puro e simples abstrair dela. A própria ideologia é somente um dos aspectos dessa história. (MARX; ENGELS, 1980, p. 18).
}

Não se trata de negar o desenvolvimento das ciências particulares e da tecnologia, assunto enfatizado por Marx e por Engels em vários escritos, mas de conceber um "sistema" (o termo não é desses clássicos) que abstratamente apreenda a totalidade da realidade como uma totalidade pensada, ou o concreto pensado como "síntese de múltiplas determinações".

Eles não fogem de uma perspectiva que, sendo teleológica (e estou usando este termo em seu sentido etimológico ${ }^{3}$ ), possui uma axiologia (não simplesmente como "teoria dos valores", mas como entendimento das determinações e dos valores basilares que explicitam as ações dos homens), caracterizada pelo permanente revolucionar das forças produtivas e relações de produção; que se expressa na luta de classes como expressão das contradições existentes na história dos homens; uma axiologia que desemboca não no estabelecimento da ética, da estética ou de qualquer dimensão moral como fundamento para a elaboração dos homens, mas na perspectiva de entender a revolução como expressão teórica dos valores humanos como demiurgo e sua própria história, portanto, uma axiologia fundada na politica enquanto luta de classes.

\section{Modo de produção como categoria central da concepção marxista}

Estabelecidos os pressupostos fundamentais da concepção materialista dialética da história, gostaria de rapidamente me reportar a alguns estrangulamentos que o marxismo encontra nas várias discussões presentes na pesquisa educacional - que ora retoma uma perspectiva essencialista do trabalho, o 
trabalho como uma essência (metafísica) do ser, ou que toma a educação como princípio explicativo do homem em sua vida em sociedade, a educação como expressão da essência do homem, quer colocando a ênfase no trabalho, quer na cultura que também acaba sendo tomada como expressão essencialista do ser humano. A partir dessa discussão, tenho buscado me contrapor a essa visão essencialista, colocando ênfase nas condições materiais pelas quais o homem produz sua existência biológica, social e intelectual. Para tanto, tenho colocado ênfase na categoria modo de produção a partir da obra de Marx e Engels, particularmente na obra conjunta $A$ ideologia alemã, primeira parte "Feuerbach: oposição entre a concepção materialista e a idealista" (MARX; ENGELS, 1980, p. 11). Ao fazerem Marx e Engels a explicitação das premissas que partiam, fundamentaram nos seguintes termos a materialidade onto-gnosiológica do entendimento da história dos homens:

\begin{abstract}
As premissas de que partimos não constituem bases arbitrárias, nem dogmas; são antes bases reais de que só é possível abstrair no âmbito da imaginação. As nossas premissas são os indivíduos reais, a sua acção e as suas condições materiais de existência, quer se trate daquelas que encontrou já elaboradas quando do seu aparecimento das que ele próprio criou. Estas bases são portanto verificáveis por vias puramente empíricas.

A primeira condição de toda a história humana é evidentemente a existência de seres humanos vivos. O primeiro estado real que encontramos é então constituído pela complexidade corporal desses indivíduos e as relações a que ela obriga com o resto da natureza. [...] Toda historiografia deve necessariamente partir dessas bases naturais e da sua modificação provocada pelos homens no decurso da história.

Diversamente dos animais, diferença que não é dada pela consciência ou pela religião "e tudo quanto se quiser como distinção entre os homens e os animais" (idem, p. 19), pois estes instintivamente satisfazem suas necessidades, os homens têm, antes de qualquer outra coisa, que produzir os meios necessários ao seu próprio existir. A produção de sua existência, é assim o processo pelo qual os homens produzem sua própria vida material. $\mathrm{O}$ recurso à citação se faz novamente necessário:

Pode-se referir a consciência, a religião e tudo o que se quiser como distinção entre os homens e os animais; porém, esta distinção só começa a existir quando os homens iniciam a producão dos seus meios de vida, passo em frente que é conseqüência da sua organização corporal. Ao produzirem os seus meios de existência, os homens produzem indiretamente a sua própria vida material.

A forma como os homens produzem esses meios depende em primeiro lugar da natureza, isto é, dos meios de existência já elaborados e que lhes é necessário reproduzir; mas não deveremos considerar esse modo de produção deste único ponto de vista, isto é, enquanto mera reprodução da existência física dos indivíduos. Pelo contrario, já constitui um modo determinado de atividade de tais indivíduos, uma forma determinada de manifestar a sua vida, um modo de vida determinado. A forma como os indivíduos manifestam a sua vida reflete muito exatamente aquilo que são. O que são coincide portanto com a sua produção, isto é, tanto com aquilo que produzem como com a forma como produzem. Aquilo que os indivíduos são depende portanto das condições materiais da sua produção. (MARX; ENGELS, 1980, p. 18)
\end{abstract}

Assim considerado, ao mesmo tempo em que entendem que o modo como os homens produzem sua existência [isto é, o modo de produção] é uma premissa fundamental, também registram que o modo de produção não deve ser considerado como "mera reprodução da existência física dos indivíduos" (idem, ibidem), mas como um modo determinado de atividade e de manifestação da vida, isto é, como um "modo de vida determinado", em que o que se produz é indissociável da forma como os homens produzem.

Homens determinados, produzindo de um modo determinado, estabelecendo uma teia de relaçôes entre os homens e destes com a natureza, foi assim que Marx e Engels teceram teoricamente seu 
entendimento quanto ao modo pelo qual os homens se produzem e produzem sua existência. Nessa teia de relações, as forças produtivas, a propriedade dos meios de produção, as relações de produção, a divisão social do trabalho, as relações sociais (ou a estrutura social), as relações políticas (e o Estado), as representações (ou a consciência dos homens), as ideologias (como teorizações invertidas de um mundo invertido) vão aparecendo teoricamente - como outras categorias - expressando a complexidade contraditória do existir social dos homens, desvelando um encadeamento sincrônico e diacrônico que tem, em última instância, na materialmente do existir do homem, a categoria modo de produção como ponto fulcral.

A perspectiva onto-gnosiológica pela qual pressupuseram o conhecimento como expressão de uma realidade materialista existente, foi exposta de uma forma a que deixasse claro que não pressupunham a primazia da idéia, do pensamento absoluto que se auto-engendra; que não tomavam como ponto de partida o que os homens dizem, imaginam e pensam; que não se centravam sobre o dito, pensado, teorizado ou documentado pelos homens; mas que se devia partir do processo de vida real, buscando teoricamente (isto é, abstratamente) apreender o viver dos homens, seu modo de produção, suas relações naturais e sociais, suas organizações e as instituições que as instituem, suas representações, suas teorizações.

Neste ponto considero imprescindível a citação do que considero a mais bela página d'A Ideologia Alemã:

Contrariamente à filosofia alemã, que desce do céu para a terra, aqui parte-se da terra
para atingir o céu. Isto significa que não se parte daquilo que os homens dizem,
imaginam e pensam nem daquilo que são nas palavras, no pensamento na imaginação e
na representação de outrem para chegar aos homens em carne e osso; parte-se dos
homens, da sua actividade real. É a partir do seu processo de vida real que se representa
o desenvolvimento dos reflexos e das repercussões ideológicas deste processo vital. [...]
Assim, a moral, a religião, a metafísica e qualquer outra ideologia, tal como as formas de
consciência que lhes correspondem, perdem imediatamente toda a aparência de
autonomia. Não tem história, não tem desenvolvimento; serão antes os homens que,
desenvolvendo a sua produção material e as sua relações materiais, transformam, com
esta realidade que lhes é própria, o seu pensamento e os produtos desse pensamento.
Não é a consciência que determina a vida, mas sim a vida que determina a consciência.
Na primeira forma de considerar este assunto, parte-se da consciência como sendo o
indivíduo vivo, e na segunda, que corresponde à vida real, parte-se dos próprios
indivíduos reais e vivos e considera-se a consciência unicamente como sua consciência.
(MARX; ENGELS, 1980, p. 26)

Mas gostaria de enfatizar que Marx e Engels não tomaram a categoria modo de produção como uma categoria geral e abstrata, idealizadora e mistificadora, a-histórica, mecânica ou determinista. Ao contrário, trata-se de categoria teórica que expressa relações fundadas no pressuposto de homens que, cotidiana e historicamente, produzem e reproduzir as condições necessárias à sua existência física, social e espiritual. É a categoria basilar de uma concepção que busca apreender o processo de desenvolvimento real dos homens, realizados sob condições historicamente determinadas.

Esta forma de considerar o assunto não é desprovida de pressupostos. Parte de premissas reais e não as abandona um único instante. Estas premissas são os homens, não isolados nem fixos de uma forma imaginaria qualquer, mas apreendidos no seu processo de desenvolvimento real em condições determinadas, desenvolvimento este 
que é visível empiricamente. Desde que se represente este processo de atividade vital, a história deixa de ser uma coleção de fatos sem vida, como a apresentam os empiristas, e que são ainda abstratos, ou a ação imaginaria de sujeitos imaginários, como a apresentam os idealistas.

É onde termina a especulação, isto é, na vida real, que começa a ciência, positiva, a expressão da atividade prática, do processo de desenvolvimento pratico dos homens. É nesse ponto que termina o fraseado oco sobre a consciência e o saber real passa a ocupar o seu lugar. Ao expor a realidade, a filosofia deixa de ter um meio onde possa existir de forma autônoma. (MARX; ENGELS, 1980, p.26)

A materialidade e a historicidade do real devem constituir-se, necessariamente, em premissas onto-gnosiológicas. Uma vez observada a aguda crítica que fizeram às formulações idealistas, formuladas a partir da crítica à Hegel e à Escola Hegeliana, a crítica à Feuerbach e seu materialismo fenomênico e ahistórico é fundamental para a construção de uma perspectiva ao mesmo tempo materialista, dialética e bistórica.

[...] Para Feuerbach, a "concepção" do mundo sensível limita-se, por um lado, à simples contemplação deste ultimo e, por outro, ao simples sentimento. Refere-se ao "Homem em vez de se referir aos "homens históricos reais. "O homem" é na realidade "o alemão”. [...] Para eliminar estes objetos é-lhe necessário refugiar-se num duplo ponto de vista: entre uma visão profana que apenas se apercebe daquilo "que é visível a olho nu" e uma outra mais elevada, filosófica, que alcança a "verdadeira essência das coisas". Não vê que o mundo sensível em seu redor não é objeto dado diretamente para toda a eternidade, e sempre igual a si mesmo, mas antes o produto da indústria e do estado da sociedade, isto é, um produto histórico, o resultado da atividade de toda uma série de gerações cada uma das quais ultrapassava a precedente, aperfeiçoando a sua indústria e o seu comércio, e modificava o seu regime social em função da modificação das necessidades. [...] (MARX; ENGELS, 1980)

Enquanto materialista Feuerbach nunca fazia intervir a história; quando aceitava a história, não era materialista. Nele, historia e materialismo eram coisas completamente separadas, o que de resto já é suficientemente explicado pelas considerações precedentes. (idem, p. 33)

Marx retomou de modo sistemático a discussão sobre modo de produção no Prefácio à Crítica da Economia Politica, em grande medida retomando sinteticamente a discussão feita em A ideologia alemã. Os fundamentos dessa visão histórica, com a expressão teórica que deram a ela, foi objeto de análise de Marx e Engels em várias de suas obras. Tenho feito o arrolamento dos títulos de algumas dessas obras, colocando-me o desafio para a continuidade dos estudos, aprofundamento e sistematização do tema: Formações econômicas pré-capitalistas (Marx); Origem da Família, da propriedade privada e do Estado (Engels); Sobre o papel do trabalho na transformação do maçado em Homem (Engels); Principalmente a gigantesca e magna obra de Marx, O Capital.

Gostaria de colocar um parênteses neste ponto, em função da consideração de muitos quanto a precariedade e equívocos de Engels, enfaticamente tornado segundo violino. Não há como pressupor que Engels tenha uma análise diferenciada em relação à questão, pois em sua obra Do socialismo utópico ao socialismo científico, não são as idéias, os discursos, ou o os pensamentos dos homens que explicam as transformações históricas do homem, mas é o modo de produção que possibilita o entendimento do que os homens produzem, de como se organizam e como pensam. Apesar de longa, a citação é elucidativa quanto ao posicionamento engelsiano: 
[...] a produção, e com ela a troca dos produtos, é a base de toda a ordem social; de que em todas as sociedades que desfilam pela história, a distribuição dos produtos, e juntamente com ela a divisão social dos homens em classes ou camadas, é determinada pelo que a sociedade produz e como produz e pelo modo de trocar os seus produtos. De conformidade com isso, as causas profundas de todas as transformações sociais e de todas as revoluções políticas não devem ser procuradas nas cabeças dos homens, nem na idéia que eles façam da verdade eterna ou da eterna justiça, mas nas transformações operadas no modo de produção e de troca; devem ser procuradas não na filosofia, mas na economia da época de que se trata. Quando nasce nos homens a consciência de que as instituições sociais vigentes são irracionais e injustas, de que a razão se converteu em insensatez e a bênção em praga, isso não é mais que um indício de que nos métodos de produção e nas formas de distribuição produziram silenciosamente transformações com as quais já não concorda a ordem social, talhada segundo o padrão de condições econômicas anteriores. E assim já está dito que nas novas relações de produção têm forçosamente que conter-se — mais ou menos desenvolvidos — os meios necessários para pôr fim aos males descobertos. E esses meios não devem ser tirados da cabeça de ninguém, mas a cabeça é que tem de descobri-los nos fatos materiais da produção, tal e qual a realidade os oferece. (ENGELS, [199-], p. 49)

É forçar muito a análise pressupor qualquer secundaridade ou desimportância da contribuição de Engels. Fecho aspas sobre a contribuição de Engels sobre o assunto, recomendando a leitura de duas obras: a primeira - A Situação da Classe Trabalhadora na Inglaterra - uma obra de 1845 e que constituiu uma primeira sistematização do autor sobre a precariedade da condição do trabalhador inglês e que decorria da exploração a que estava submetido; e também para outra obra, esta de 1884 - a Origem da família, da propriedade privada e do Estado - que, apesar de revelar o encanto que teve com a obra de Morgan, $A$ Sociedade Antiga, de 1877, é suficiente para recuperar grande atualidade teórica de Engels nestes tempos de retomada aos messianismos e misticismos criacionistas.

\section{Educação e modo de produção capitalista}

Sobre a perspectiva marxista e a educação penso que meu entendimento sobre o assunto seja público, uma vez que está expresso principalmente no livro Marxismo e educaşão, que organizei juntamente com Dermeval Saviani (LOMBARDI; SAVIANI, 2005).

Em primeiro lugar, bem cabem as críticas de Marx e Engels às perspectivas com que a educação tem sido tratada contemporaneamente. Como uma idéia que paira sobre nossas cabeças, iluminando nossos destinos; como uma expressão de pensamentos e idéias de sujeitos mais ou menos ilustres e que marcam toda a educação de uma época; como discurso articulado e passível de conhecimento; como memória...; como fenômeno empiricamente observável... etc.

Ao contrário dessas abordagens, as observações já elencadas de Marx e Engels com relação às tradições filosóficas alemãs, objeto da ácida e satírica crítica, produzida como "acerto de contas" com a trajetória anterior, permitem buscar um entendimento mais materialmente determinado, histórico, contraditório, objetivamente apreensível enquanto "concreto pensado".

Partindo do entendimento de que a educação é um campo de atividade humana e que os profissionais da educação não construíram esse campo segundo suas próprias idéias, penso a educação como conformada por condições materiais e objetivas, por relações que correspondem às forças 
produtivas e relações de produção adequadas aos diferentes modos e organizações da produção, historicamente construídas pelos homens e particularmente consolidades nas mais diferentes formações sociais. Em linhas gerais, a discussão da educaşão a partir de sua articulação com o modo capitalista de produção, a partir da obra marxiana e engelsiana, expressa 3 movimentos articulados (ou indissociados, a não ser para efeitos didáticos):

1) Possibilita uma profunda crítica do ensino burguês;

2) Traz a tona, sob as condições desse modo de produção, como se dá a educação do proletariado;

3) Contraditoriamente, a crítica do ensino burguês e o desvelamento da educação realizada para o proletariado, torna possível delinear a premissas gerais da educação do futuro... não como utopia, mas como projeto estratégico em processo de construção pelo proletariado. Compondo um projeto educacional que articula teoria e prática, o saber e o fazer, de forma a vislumbrar a educação integral do homem, uma educação omnilateral.

\section{Considerações finais:}

Contraditoriamente a visão particularista e a histórica corrente, penso que a educação expressa as condições sociais dos diferentes momentos históricos. Quando se pensa na transição do feudalismo para o capitalismo, a formatação que a educação adquire uma perspectiva manufatureira do trabalho educacional e da organização do ensino e do trabalho educativo, como foi registrada na teorização comeniana. A maquinaria e a grande indústria reorganizou a educação e o ensino de modo a expressar a fábrica e a organização do trabalho na fábrica. Gradativamente foi sendo introduzindo a divisão do trabalho fabril na escola, com o ensino seriado, ministrado em níveis e graus diferenciados, tal qual se organiza o trabalho fabril. E, principalmente, articulou-se uma estrutura educativa que, pela primeira vez na história, tem na escola o seu grande palco de realização. A passagem da grande indústria para o monopólio e as grandes corporações monopolistas, encontrou na perspectiva tecnicista, enquanto expressão do taylorismo, a sua grande expressão também na reflexão sobre a educação. Diferenciando a escola tradicional, "velha", cria-se a teoria de uma Nova Escola. A velha educação se articulava na escola, enquanto um ensino seriado, com conteúdo pré-definido, pré-estabelecido, articulado e organizado nos manuais. A teorização educacional da nova escola passa a reivindicar uma educação não mais centrada externamente, mas centrada no próprio sujeito, no próprio educando, colocando no educando a responsabilidade pelo saber e pelo não saber. Teve na ampliação do sistema educacional a sua base e fundamento, não sendo por outro motivo que os grandes sistemas de educação foram estar se forjando no final do século XIX, nação após nação. A educação contemporânea passou a se forjar no momento em que o modo capitalista de produção em sua fase monopólica sofreu e vivenciou um novo momento organizativo, caracterizado como toyotista, que é muito bem teorizado pelos franceses, desde a crítica ao sistema educacional francês, com Stablet e Passerron, até a crítica à instrumentação ideológica dessa escola e dessa educação, feita por Althusser, que certamente merecem uma retomada, como já têm bem salientado Décio Saes e Ester Buffa, revendo as críticas ao estruturalismo como sendo uma perspectiva 
meramente reprodutivista, como bem assinalou Marcos Cassin, em seu capítulo sobre o tema na coletânea Marxismo e Educaşão, já referenciada (LOMBARDI; SAVIANI, 2005) .

Se quisermos pensar as discussões sobre a educação, inclusive retomando a tradição e a trajetória marxista, tal qual se expressa na elaboração marxiana e engelsiana, é necessário pensar uma educação que se direcione para além do capital. Uma educação que contribua para o proletariado se organizar e criar as condições para um salto de qualidade na sua luta revolucionária contra o capitalismo. E isto não é algo para o futuro. É algo que já vem se dando desde o momento em que o proletariado passou a reivindicar, em contraposição à educação burguesa, uma educação que articule trabalho manual com trabalho intelectual, que lhe possibilite uma formação integral, uma educação que ultrapasse os limites e a alienação posta na educação burguesa, contribuindo para a construção e socialização de uma perspectiva crítica de pensar o mundo, e que desde o século XVIII encontra sua expressão, não mais numa imposição de uma educação única, pelo menos na formatação de algumas grandes elaborações teóricas e práticas sobre a educação. O estabelecimento dos sistemas educacionais não mais se deu em uma perspectiva unilateralmente burguesa, mas a política educacional burguesa foi obrigada a absorver as contraposições e as reivindicações do proletariado em termos educacionais. Ainda hoje vemos diferentes projetos educacionais que estão em disputa, e isto não se dá a nível pura e simplesmente do pensamento, não são pura e simplesmente idéias pedagógicas diferenciadas, mas de implementação de escolas e até organizações educacionais que politicamente se situam para além do capital. Não são simples idéias que expressam os embates entre as classes em disputa na sociedade, mas instituições e práticas educativas que, ainda sob a hegemonia burguesa, apontam para a construção de uma nova sociedade, para a produção histórica de relações sociais solidárias e emancipatórias.

Enquanto a burguesia, em plena e profunda crise estrutural do capitalismo, festeja a "queda do muro", um espectro continua a rondar o mundo: o comunismo.

\section{Referências}

ENGELS, F. Do socialismo utópico ao socialismo científico. São Paulo: Moraes, [199-]

FERREIRA, A. B. H. Novo dicionário da lingua portuguesa. Rio de Janeiro: Nova Fronteira, [19--]

MARX, K.; ENGELS, F. A Ideologia Alemã: crítica da filosofia alemã mais recente na pessoa dos seus representantes Feuerbach, B. Bauer e Stirnes, e do socialismo alemão na dos seus diferentes profetas. Lisboa: Presença; Martins Fontes, 1980. v. 1-2.

LOMBARDI, J. C.; SAVIANI, D. Marxismo e educação: debates contemporâneos. Campinas: Autores Associados; HISTEDBR, 2005.

\footnotetext{
Notas:

1 Conferência proferida durante o debate Modo de Produção e Educaşão realizado na Faculdade de Educação - UNICAMP. Transcrição feita por Elza Peixoto, complementando os apontamentos básicos da fala apresentados pelo autor.

2 Bolsista de Produtividade em Pesquisa 2. Doutorado em Educação pela Universidade Estadual de Campinas (1993). Professor Assistente Doutor da Universidade Estadual de Campinas. Email: zezo@unicamp.br
} 
${ }^{3}$ Teleologia: (do grego $\tau \dot{\lambda} \lambda o \varsigma$ - teleio, + logía) estudo dos fins ou da finalidade da sociedade, humanidade e natureza. Teleológico é o argumento ou explicação que relaciona um fato ou conjunto de fatos com sua causa; ou é o sistema de relações entre meios e fins (FERREIRA, [s.d.], p. 1362). 